\title{
Researches about factor market distortions on the impacting factors of international technology spillover
}

\author{
Xiaoyang $\mathrm{Jia}^{1 *}$, Xiaoyu $\mathrm{Liu}^{2}$, and Xiaofei $\mathrm{Liu}^{1}$ \\ ${ }^{1}$ Shandong Foreign Trade Vocational Collage, No.201, Jufeng Road, Licang District, Qingdao, \\ 266000 \\ ${ }^{2}$ Qingdao University of Technology, No.236, Fuzhou South Road, Jiaozhou City, 61785377@qq.com
}

\begin{abstract}
In this paper, we selected 1999-2015 Provincial Panel Data in China statistical yearbook. The effects of factor market distortions on international technology spillovers are discussed. In the factor market distorted elements of the market to promote the rapid growth of the economy in the short term, it may inhibit the international technology spillover effect, but the move is beneficial to realize the sustainability of high quality economic growth. The results showed that the technology spillover effects of the import trade, FDI and patent applications presented different feature in different stages. The article from the perspective of the development of technology breakthrough summarizes factors price distortions on the international technology spillover mechanism and study with the policy changes, elements of the market to improve dynamic changes, the factor price distortion effect of international technology spillovers stage effect.
\end{abstract}

\section{Introduction}

The technological progress is the power and source of a country's economic growth, but also reflects the quality of economic development. The international technology spillover is one of the most important ways of technological progress. In previous years, China in the economic development of most importance to economic growth rate, local government introduced various policies, through the elements of market pricing, distribution rights to control the distortion factor markets, in order to provide preferential government policies, attract domestic and foreign enterprises to invest and set up factories, the ultimate objective is to boost GDP. Worth noting is that China is in the process of economic restructuring, the elements of the market distortions become a widespread phenomenon ( $\mathrm{Lu}$, Wen-Min etc., 2006), its performance as the factor market segmentation, factor price of underestimating (Zhang Jie, 2011; Chen Yongwei, Wei Min Hu, 2011; Bing Zhan Shi, 2016). Factor market distortion in a certain extent stimulates the local government investment at the price of resources. The distorted elements modes should be given. Chinese economy development rely on distorted elements of the market price, the extensive growth mode not only cannot

*Corresponding author: jiaxyqd@163.com 
achieve the sustainable growth of high quality material resources consumption, and may be required for international technology spillover of market of soil loss, but cannot reach a convergence technology, catch up with and surpass the developed countries (Banerjee, 2005; Guner, 2016) [1]. This paper starts from the perspective of the Chinese factor market distortions in the, considering the shortcomings of existing research into phases of ideas, examines national policy guidance before and after the transformation, the elements of the market distortion phase influence on international technology spillover effect[2]. This article mainly includes the following aspects: one is to enrich the existing literature on the theory of factor price and will distort international technology spillovers associated, and its model, clarifies the theoretical relationship between; two is the construction of capital and labor factor price distortion index, improve the existing methods which were quantified, and investigate the changes of capital, the labor factor price distortion before and after the change of national policy guidance, and stage division; three is the use of empirical test, 2SLS OLS price and GMM methods distorted different effects in different phases of international technology spillover effect, the effect of the stage characteristics significantly depends on the policy oriented transformation and factor price distortion, so this paper focuses on stage characteristics analysis. Arrangement of the structure of the rest of the paper is as follows: the second section is the theoretical model; in the third part, econometric model design, index construction and data source; the fourth part of the sample is divided into two sub intervals, capital, labor factor prices distorted effect of international technology spillovers empirical testing and result analysis; finally is the conclusion of this paper.

\section{The model design, indicators and data sources}

In an open economy, factor price distortion technology spillover effect on international trade, FDI and patent applications will affect. This paper chooses 1999-2015 provincial panel data. It measures the variables as follows:

\subsection{Factor price distortion measure}

The basic idea is to estimate the production function to calculate the marginal output elements, i.e. elements should be paid, then do the ratio of elements and the actual reward is obtained, factor price distortion index. Set the production function for the following form. In the process of estimation $\beta_{K i t}$ and $\beta_{L i t}$, for the selection of the regression equation, panel data regression, sub annual, sub provinces etc [3]. Respectively. Regression, the regression shows the various regression methods measure results are basically the same, equation 1 is the overall regression the simplest method.

$$
Y_{i t}=\mathrm{TFP}_{i t} K_{i t}^{\beta_{\mathrm{K} i t}} L_{i t}^{\beta_{\mathrm{Lit}}}
$$

The elements of the marginal output and TFP respectively:

$$
\begin{gathered}
M P_{K i t}=T F P_{i t} \beta_{K i t} K_{i t}^{\beta_{K i t}-1} L_{i t}^{\beta_{L i t}}=\beta_{K i t} Y_{i t} / K_{i t} \\
M P_{L i t}=T F P_{i t} \beta_{L i t} K_{i t}^{\beta_{K i t}} L_{i t}^{\beta L_{i t}-1}=\beta_{L i t} Y_{i t} / \mathrm{L}_{i t} \\
\operatorname{lnTFP} P_{i t}=\ln Y_{i t}-\beta_{K i t} \ln K_{i t}-\beta_{L i t} \ln L_{i t}
\end{gathered}
$$


In the process of equation 2 and equation 3, estimation $\beta_{K i t}$ and $\beta_{L i t}$, for the selection of the regression equation, panel data regression, sub annual, sub provinces etc. Regression, the regression shows the various regression methods measure results are basically the same, here is the overall regression the simplest method. In the marginal output to obtain elements $M P_{k t}, M P_{L t}$, the price of capital $r_{i t}$, the price of labor $w_{i t}$, the price distortion and total distortion calculation of various elements. In the equation4, individual economy workers and employees is in the same in hypothesis.

\subsection{Data sources}

This paper selects Chinese 1999-2015 provincial panel data analysis. Among them, the area of GDP, CPI index, the number of patent applications, labor remuneration, the price index of investment in fixed assets and total investment in fixed assets from the "China statistical yearbook". Each year the loan interest rate from the people's Bank of China. The area over the patent application authorization from the Ministry of science and technology, science and technology statistics database Chinese. Chinese technology overflow amount, to go abroad to import technology overflow abroad direct investment in China and the application amount of total authorized patents in China are derived from the "China Statistical Yearbook" and "national intellectual property rights Bureau statistics yearbook".

\section{The analysis of the test results and the mechanism}

\subsection{Statistical analysis of factor price distortions}

Do the ratio of payments due and the elements of the real reward, by factor price distortion index. If the ratio is greater than 1, that is greater than the actual income factors deserve elements, factor prices showed the reverse distortion, whereas the positive factor price distortion. Since 2007, labor factor price distortion index decreases, distortion factor improved significantly, reflecting the reform of China's price system is better to implement the elements. Is total factor twist, distortion degree decreased from 6.8 in 2006 to 2007 5.6, decline range is the biggest, twist after amplitude average value is about 5.4, which shows that the degree of marketization of our country gradually deepened, especially in 2007 as a turning point, policy oriented changes the factor market distortion levels decreased significantly, before and after the change of the more prominent.

\subsection{The analysis of the test results and the mechanism}

The statistical analysis of factor price distortions results showed that variables are for the same order integration variables, further co-integration test found that variables there is a long-term equilibrium relationship, so as to avoid the spurious regression. In the model, capital and labor factor twist term, factor and the overall distortion and import and export volume and foreign capital introduction and technical achievements of the interactive item may be a multicollinearity problem and influence the results of the regression significantly [4]. Therefore, the reduced polynomial or interaction effect model reduces the degree of collinearity between variables. The mechanism of inhibition of factor price distortion technology spillover effect can be summarized as resource trap effect. Want to import competing sectors through competition incentive and imitation effect and improve the variety and quality of the production of intermediate goods and capital goods, thus reversing the import of foreign domestic enterprises situation, is an extremely slow process 
[5].Factor price distortions has no inhibiting effect on technology spillovers, the resource trap effect can better solve the problems. In the multi-national corporation, master advanced technology, using new knowledge, management, accounting and marketing techniques or production line organization may have a demonstration effect and human capital flow effect on the local competitors, but more foreign owned enterprises will tend to enter the effect is suppressed[6]. Obviously, this phase factor market distortion is serious, the inhibition of FDI technology spillover effect. The coefficient of labor factor variable is distorted significantly negative, and the so-called demographic dividend government and enterprises by lowering the wages of workers. Compared with the results of the first stage of the method of instrumental variables regression, capital element distortion coefficients by a significant negative variable is significantly positive, suggesting that policy oriented transformation, factor market distortions reduce, bring about significant technology spillover effects of FDI through competition incentive effect, demonstration imitation effect, way to the east country. Similarly, labor distortion coefficients by a significant negative variable is significantly positive, indicating that the change in policy, elements of the degree of marketization progress make FDI through the effect of human capital, skill talent flow effect and so on ways to promote the technology spillover.

Table 1. Factor price distortions stage test results on international trade technology spillover effect

\begin{tabular}{|c|c|c|c|}
\hline Explain Variable & 2SLS & FE & 2SLS \\
\hline \multirow{2}{*}{$S_{i t}^{d-r d k}$} & -0.140 & -0.112 & 0.085 \\
& $(-0.89)$ & $(-1.34)$ & $(1.02)$ \\
\hline \multirow{2}{*}{$S_{i t}^{d-r d l}$} & 0.086 & 0.159 & 0.163 \\
\hline \multirow{2}{*}{ Dist $K_{i t}$} & $(1.64)^{*}$ & $(0.77)$ & $(2.01)^{* *}$ \\
\hline \multirow{2}{*}{ Dist $_{i t}$} & -0.078 & 0.379 & 0.062 \\
& $(-3.12)^{* * *}$ & $(1.46)^{*}$ & $(2.17)^{* *}$ \\
\hline \multirow{2}{*}{$\ln Y_{i t}$} & -0.049 & -0.154 & 0.106 \\
& $(-1.89)^{* *}$ & $(-1.23)$ & $(1.64)^{*}$ \\
\hline \multirow{2}{*}{$\ln K_{i t}$} & 1.915 & 2.367 & 2.528 \\
\multirow{2}{*}{$\ln L_{i t}$} & $(4.04)^{* * *}$ & $(3.94)^{* * *}$ & $(4.53)^{* * *}$ \\
\hline \multirow{2}{*}{${ }_{i s t_{i t}}^{*} t r_{i t}$} & 0.149 & 0.578 & 0.234 \\
& $(0.86)$ & $(1.48)^{*}$ & $(1.74)^{*}$ \\
\hline \multirow{2}{*}{$C_{i t}$} & 0.121 & 0.206 & 0.171 \\
& $(1.96)^{* *}$ & $(2.05)^{* *}$ & $(2.37)^{* *}$ \\
\hline$R^{2}$ & -0.045 & 0.056 & 0.084 \\
& $(-2.83)^{* *}$ & $(2.62)^{* *}$ & $(2.99)^{* * *}$ \\
\hline
\end{tabular}

Note: The numbers in parentheses in Table t Statistics symbol***, **, *respectively at the $1 \%$ level, $5 \%$ and $10 \%$ of the significant variables.

From Table 1 shows in the first stage, capital, labor factor price distortion coefficients are negative and overall factors price distortions and foreign capital to introduce the degree coefficient for the interaction term is also negative, and the coefficient through the test of significance of $5 \%$, which indicates that the factor price distortion inhibited the technology spillover of FDI in China. Secondly, the use of factor price distortion make enterprises more inclined to rely on cheap elements to profit, and investment will tend to be more funds for investment in fixed assets, the industrial structure, curing technology spillover is blocked. Thirdly, capital, labor and other factors underestimated the price will stimulate domestic enterprises and entrepreneurs in the intensive use of tangible elements, and have 
less pressure and power investment in independent innovation, technology spillover is difficult to effectively undertake and internalization of multi-national corporation.

\section{Conclusion}

Depends on its own R\&D capability and the absorption of foreign technology spillovers to improve the technology progress level of a country or region, the international technology diffusion as a technology spillover is the important channel, is an important source of technological innovation capability is weak developing countries and regions in the technological progress[7]. Theoretically speaking, in the market under the condition of complete, the mechanism can play their respective roles. But China's market-oriented reform process of marketization degree lag in the asymmetric phenomenon in the product market and factor price formation mechanism by administrative monopoly and government regulation of the distortions, mainly for distortion directly, such as land, capital and labor prices low estimate; distorts overhead, tariffs, import quotas, and exchange rate policy influence[8]. Because the market is not perfect, non optimal allocation of factors of production resources in the national economy, the factor price of opportunity cost deviation or departure. This will cause the regression results of the first three parts technology spillover model test in the first stage. And after the government's adjustment of the policy, promote to the elements of the market process, and the survival environment of the enterprise in the market regulation and factor market distortions can be solved to a great extent, the related theories of the role play, international technology spillover effect improved significantly.

At present, the world of scientific inventions and technological achievements mainly from developed countries, the global R\&D investment is mainly from developed countries. In general, the developed countries are the leading country scientific invention and technological innovation, while the developing countries and regions in the country to follow and imitate technology belong to. Technology progress of developing countries and regions not only need research and innovation in China, largely reliant on foreign sources of technology. While the international technology spillover is one of the main ways of developing countries of technological progress, has a significant effect on the host countries to enhance the quality of economic development. In the original phase (1999-2007), local governments controlled the resource elements' pricing power leading to factor market distortions, thus weakening and barraging the international spillover effects. In policy orientation phase (2008-2015), government payed more attention to the quality of economic development, the degree of market distortion factors significantly reduced and the role of market mechanism played, international technology spillover got an increase gradually. This article from the perspective of the development of technology breakthrough summarizes factors price distortions on the international technology spillover mechanism and study with the policy changes, elements of the market to improve dynamic changes, the factor price distortion effect of international technology spillovers stage effect.

Acknowledgments: This work is supported by Shandong Higher School Humanities And Social Science Program Project(J17RB149).

\section{References}

1. Banerjee, A., and Duflo, E., 2005 .Growth Theory through the Lens of Development Economics. 
2. Banerjee, A., and Munshi, K., "How Efficiently is Capital Allocated? Evidence from the Knitted Garment Industry in Tirupur", Review of Economic Studies (Jan. 2004), 19-42

3. Buera, F., Kaboski, J., and Shin, Y., "Finance and Development: A Tale of Two Sectors", American Economic Review (May 2011), 1964-2002.

4. Coe, D. T, Helpman, E., "International R\&D Spillovers", European Economic Review (May 2005), 859-887.

5. Lu, Wen-Min, Liu, John S. , “The Marginal Efficiency Of Capital: Reply To Fuller's Rejoinder", Quarterly Journal of Austrian Economics(Jan. 2015), 61-67.

6. Galindo, A., Schiantarelli, F., and Weiss, A., "Does Financial Liberalization Improve the Allocation of Investment?" Journal of International Economics (Feb. 2016) ,562587.

7. Gill, I. S., Kharas, H. J., Bhattasali, D., “An East Asian Renaissance: Ideas for Economic Growth”, World Bank Publications, 2007.

8. Guner, N., Ventura, G., and Xu, Y., "Macroeconomic Implications of Size-Dependent Policies", Review of Economic Dynamics (Apr. 2016), 721-744. 